\title{
Interações no ambiente de cuidado: explorando publicações de Enfermagem
}

\author{
Interactions in the environment of care: exploring Nursing publications
}

Interacciones en el ambiente de cuidado: explorando publicaciones de Enfermería

\section{Gabriela Marcellino de Melo Lanzoni', Juliana Cristina Lessmann", Francisca Georgina Macêdo de Sousa"', Alacoque Lorenzini Erdmann" ${ }^{\text {, }}$, Betina Hörner Schlindwein Meirelles"}

\author{
' Universidade Federal de Santa Catarina. Departamento de Enfermagem. Programa de Pós-Graduação em Enfermagem. \\ Florianópolis-SC, Brasil. \\ " Universidade Federal de Santa Catarina. Curso de Graduação em Enfermagem. Florianópolis-SC, Brasil. \\ II' Universidade Federal do Maranhão. Curso de Enfermagem. São Luís-MA, Brasil. \\ Iv Universidade Federal de Santa Catarina. Departamento de Enfermagem. Programa de Pós-Graduação em Enfermagem. \\ Florianópolis-SC, Brasil. Pesquisadora CNPq.
}

\section{Submissão: 15/09/2009 Aprovação: 12/09/2010}

\section{RESUMO}

Revisão de literatura, utilizando a Análise Temática, com o objetivo de apreender as interações no ambiente de cuidado a partir de publicações em quatro periódicos brasileiros de enfermagem, de circulação internacional, no período de 2000 a 2007. Foi realizada leitura atenta do título, resumo e palavras-chave para seleção de textos, sendo analisados 2.548 artigos e selecionados 331. Destes, $78,6 \%$ eram pesquisas científicas e $88 \%$ apresentavam doutores na autoria. Reconheceram-se cinco unidades temáticas: atitude de interação; o processo interativo e suas finalidades; cuidado mediado e ampliado pelo processo interativo; interação prejudicada; interação como instrumento de gestão e formação do sistema de saúde. Os pesquisadores reconhecem a complexidade destas relações como fundamento do cuidado em saúde e Enfermagem.

Descritores: Enfermagem; Cuidados de Saúde; Ambiente de instituições de saúde.

\section{ABSTRACT}

Review of literature, using the Thematic Analysis, with the aim of understanding the interactions in the environment of care from publications in four Brazilian nursing journals of international circulation, in the period 2000 to 2007. We performed a careful reading of the title, abstract and keywords of 2.548 articles, of which 331 were selected. Of those 331 articles, $78.6 \%$ were scientific research and $88 \%$ had doctors in the authorship. Five thematic units were recognized: attitudes of interaction; the interactive process and its purposes; the care mediated and extended by interactive process; interaction, impaired; interaction as a tool for management and constitution of the health system. The researchers acknowledge the complexity of these relationships as foundation of health care and nursing.

Key words: Nursing; Delivery of health care; Health facility environment.

\section{RESUMEN}

Revisión de la literatura, utilizando Análisis Temático, con el objetivo de comprender las interacciones en el ambiente de cuidado a partir de las publicaciones de cuatro revistas brasileñas de Enfermería, de circulación internacional, en el período de 2000 a 2007. Hemos realizado una cuidadosa lectura del título, resumen y palabras clave de 2.548 artículos, de los cuales 331 fueron seleccionados. De los 331 artículos, 78,6\% eran de investigación científica y 88\% tenían doctores en la autoría. Cinco unidades temáticas fueran reconocidas: actitudes de interacción, proceso interactivo y sus efectos, el cuidado mediado y extendido por el proceso interactivo; interacción perjudicada; interacción como una herramienta para gestión y formación del sistema de salud. Los investigadores reconocen la complejidad de estas relaciones como la base de la atención de la salud y Enfermería.

Palabras clave: Enfermería; Prestación de atención de salud; Ambiente de instituciones de salud. 


\section{INTRODUÇÃO}

O ambiente de cuidado caracteriza-se como local aglutinador de aspectos físicos, biológicos, científicos, culturais, sociais, econômicos, entre outros, em uma teia de relações onde se torna difícil excluir ou isolar partes e que as "partes exercem ação e inter-retroação contínua"(1), levando ao estabelecimento de relações de cuidado em situações vitais que envolvem o processo saúde-doença.

O ser humano constrói suas relações sociais ocupando-se e preocupando-se com pessoas e coisas a ponto de reconhecer-se como "ser-no-mundo-com-outros" e, com isto, dedicando-se e inserindo o cuidado em tudo que lhe representa importância e valor ${ }^{(2)}$. Compreendemos que, para cuidar, o enfermeiro necessita de relações que estabeleçam proximidade entre os sujeitos e culminem com processos interativos mútuos, onde o diálogo e o contato são valorizados, sempre embasados na ética e respeito à condição do ser como sujeito de direitos, desejos e saberes.

É por meio do processo interativo que o enfermeiro realiza o cuidado, tendo em vista que as interações constituem o centro da dinâmica que compõem o mundo, sendo reconhecidas pelo encontro ou influencia entre pessoas, podendo convergir em estados de inter-relação e interdependência capazes de definir condutas, atitudes e formas de convívio individual e coletivo ${ }^{(3)}$.

A interação é um processo de percepção e comunicação entre pessoas que se manifesta por condutas verbais e não verbais dirigidas a um objetivo. Esta relação se constitui em uma experiência de aprendizagem pelas quais as pessoas interagem para enfrentar um problema de saúde, para colaborar em sua evolução e para buscar adaptar-se às situações que envolvem o processo de saúde-doença ${ }^{(4)}$.

Desta forma, compreender as interações que ocorrem no processo de cuidar demanda reconhecer as particularidades inerentes à subjetividade dos sujeitos, a multiplicidade de interpretações possíveis pela mente humana, assim como os sentimentos que estão envolvidos no processo de cuidado. Estes reconhecimentos demandam ampliar o olhar e estar aberto para a compreensão de fatos e fenômenos distintos que ocorrem em um mesmo ambiente e permeiam todas as ações de cuidado.

No entanto, a dinâmica existente entre os envolvidos no cuidado, assim como seus mecanismos e particularidades "não estão à vista"(5), sendo que, no cerne das relações, existem ideologias, aproximações, distanciamentos, ideias comuns e, ao mesmo tempo, discordantes, que se unem e se afastam ao ponto de gerarem uma 'dança interativa'. Esta relação interativa desenvolve-se na perspectiva de que o cuidado conjuga vários participantes, que conectados constituem teias estruturais que compõem e caracterizam o cuidado, identificado por um "emaranhado de redes inseridas em redes maiores"(6).

A formação de enfermeiros aliada à qualificação dos profissionais nos níveis de mestrado e doutorado tem sido enriquecida pelos grupos de estudos, que consistem em locais de permanente processo interativo. Nesta perspectiva o Grupo de Estudo e Pesquisa em Administração/Gestão em Enfermagem e Saúde (GEPADES) vem investigando e renovando conhecimentos em enfermagem. Dentre as várias discussões realizadas nesse grupo, o ambiente de cuidado tem sido objeto de estudo inserido em um projeto de pesquisa intitulado "Concepções de sistema organizacional de saúde e enfermagem pelo olhar da complexidade das práticas dos serviços de saúde em ambientes mais saudáveis". Junto a esta temática surgiram alguns questionamentos tais como: Qual a dimensão da interação no ambiente de cuidado? $O$ que a enfermagem e outras ciências têm produzido de conhecimento a cerca das interações no sistema de cuidado?

Estes questionamentos motivaram a busca de conhecimentos nas publicações de enfermagem, resultando nas discussões aqui apresentadas. Assim, este estudo tem como objetivo apreender a temática das interações no ambiente de cuidado a partir de publicações em periódicos de enfermagem.

Fundamentado nessas assertivas é que se justifica o presente estudo, posto que é preciso compreender a dinâmica existente no processo interativo de cuidar em saúde e Enfermagem para que seja possível redimensionar o cuidado e o ambiente, adequando-os às demandas e necessidades de saúde, assim como das organizações de serviços, aliando tais necessidades aos avanços científicos e tecnológicos na busca por melhores práticas para o cuidar em saúde.

\section{METODOLOGIA}

Trata-se de uma pesquisa bibliográfica, efetuada por meio de busca em periódicos da área de enfermagem, quais sejam: Revista Texto \& Contexto Enfermagem, Revista Brasileira de Enfermagem, Revista Gaúcha de Enfermagem e Revista Latino Americana de Enfermagem. O estudo privilegiou a análise qualitativa dos dados, levando-se em consideração que a pesquisa bibliográfica é aquela "desenvolvida a partir de material já elaborado, constituído principalmente de livros e artigos", e utiliza as "contribuições dos diversos autores sobre determinado assunto"(7).

Para a coleta de dados, fez-se um recorte temporal dos anos de publicações das revistas restringindo-se ao período de 2000 a 2007, por considerar que as publicações do referido período seriam mais facilmente localizadas, inclusive, disponíveis em meio eletrônico. O outro recorte foi em relação aos periódicos, escolhidos intencionalmente, levando-se em consideração o aceso e disponibilidade dos mesmos pelos pesquisadores. Nesse sentido foram selecionadas quatro revistas brasileiras de enfermagem, de circulação internacional. O acesso às revistas foi facilitado, pois estão disponibilizadas em formato impresso em biblioteca pública e também em formato digital na rede mundial de computadores.

De posse dos volumes e números, as revistas foram separadas por ano, para, em seguida, ser iniciada a leitura e identificação dos textos de interesse para o estudo. Para a coleta de dados foi utilizada a leitura de todos os títulos, resumos e descritores buscando extrair aqueles que traziam a temática das interações no cuidado em saúde e enfermagem. Caso a análise desse elemento não fosse suficiente para a seleção do artigo, pois na maioria das vezes, o processo interativo não estava exposto de forma clara e sim implicitamente colocado no texto, foi realizada leitura exploratória do artigo na sua totalidade. 
O critério utilizado para inclusão do artigo no banco de dados da pesquisa centrou-se na condição de apresentar, mesmo que de forma indireta, aspectos que permeavam a interação no processo saúde-doença. Isto é, em alguns textos, a interação emergiu a partir da análise e discussão dos autores, muito embora o termo não fizesse parte do título e/ou dos resumos.

Além da temática da interação foram identificados alguns dados considerados importantes como: titulação dos autores, modalidade do artigo e significados de interação construídos a partir dos textos. A coleta de dados foi efetuada durante o ano de 2008, sendo que fizeram parte do acervo bibliográfico 2.548 artigos, dos quais 331 foram selecionados para compor esta pesquisa.

Após a leitura e seleção dos artigos, foi iniciada a etapa de análise baseada nos pressupostos da Análise Temática, que "consiste em descobrir os núcleos de sentido que compõem uma comunicação cuja presença ou frequência signifiquem alguma coisa para o objetivo analítico visado ${ }^{\prime(8)}$. Para Minayo ${ }^{(8)}$, a noção de Tema, está ligada a uma afirmação a respeito de determinado assunto e pode ser apresentada por uma palavra, frase ou resumo. A operacionalização do estudo seguiu as três etapas da Análise Temática. A primeira etapa ou de Pré-Análise consistiu na leitura exaustiva dos artigos (leitura flutuante), seguida da organização do material (Constituição do Corpus) e a formulação de hipóteses. A segunda etapa compreendeu a exploração do material, que consistiu na codificação dos dados brutos. Por último, foi realizado o tratamento dos resultados e interpretação apresentados em unidades temáticas.

A análise e interpretação dos dados permitiu o reconhecimento de estruturas de relevância, convergindo na identificação de códigos primários e famílias de códigos que permitiram a construção de cinco unidades temáticas, apresentadas com partes textuais.

Tabela 1 - Perfil dos autores dos artigos selecionados.

\begin{tabular}{lcc}
\hline TITULAÇÃO & \multicolumn{2}{c}{$(\mathrm{n}=331)$} \\
\hline Doutores & $f$ & $\%$ \\
Doutores / Mestres & 61 & 18 \\
Doutores / Mestrandos & 94 & 28 \\
Doutores / Enfermeiros Assistenciais & 26 & 8 \\
Doutores / Doutorandos & 25 & 8 \\
Doutores / Graduandos & 18 & 5 \\
Mestres / Enfermeiros Assistenciais & 16 & 5 \\
Doutores/ Mestres/ Enfermeiros Assistenciais & 12 & 4 \\
Doutores/ Enfermeiros Assistenciais/ Graduandos & 10 & 3 \\
Doutorandos/ Mestrandos & 9 & 3 \\
Doutores/ Mestres/ Graduandos & 8 & 2 \\
Mestres & 8 & 2 \\
Enfermeiros Assistenciais & 6 & 2 \\
Doutores e outras associações de alunos de Pós-graduação e graduação & 5 & 2 \\
Doutorandos e outras associações de alunos de Pós-graduação e graduação & 9 & 4 \\
Mestres e outras associações de alunos de Pós-graduação e graduação & 8 & 2 \\
Enfermeiros Assistenciais / Graduandos & 3 & 1 \\
\hline Total & 931 & $\mathbf{1 0 0}$ \\
\hline
\end{tabular}

\section{RESULTADOS E DISCUSSÃO}

A avaliação dos artigos selecionados permitiu o reconhecimento do perfil das pessoas que escrevem, sendo a maioria deles doutores e mestres (Tabela 1). Outro fator importante foi identificar que a maioria $(78.6 \%)$ dos estudos publicados são pesquisas, seguidos de $10.6 \%$ de relatos de experiência, $5.7 \%$ de reflexões teóricas, $1.8 \%$ de estudos de revisão, $1.8 \%$ são estudos de caso e $1.5 \%$ dos estudos são ensaios teóricos.

As relações entre os seres são consideradas complexas, pois são "a um só tempo acêntricas, policêntricas e cêntricas" $^{\prime(9)}$, se auto regulam visando um cuidado participativo e transformador. Produzir conhecimento acerca destas relações torna-se tão complexo quanto o fenômeno do qual decorrem, sendo tal dificuldade motivada pela multiplicidade de reações que o ser humano desenvolve em suas relações sócio-afetivo-político e culturais e pela forma com que regula suas ações, reações e interações no mundo em que vive.

Assim, de 2.548 artigos que compunham o acervo bibliográfico desta pesquisa, apenas 331 desvelaram as características do ser humano como ser gregário e em constante interação com o mundo que o cerca, neste caso o ambiente de cuidado e seus constituintes. Tais artigos foram capazes de mostrar o ser humano como ser singular, que tenta conceber a articulação, a identidade e a diferença de todos os aspectos envolvidos no cuidado, culminando no estabelecimento de conhecimentos que fortalecem as ações em saúde e Enfermagem $^{(10)}$. As unidades temáticas que emergiram da análise dos dados estão expostas a seguir.

\section{Unidade temática 1: Atitude de interação}

A interação no ambiente de cuidado nos artigos analisados se traduz em atitudes realizadas para promover, manter ou recuperar a saúde. Com destaque para a comunicação efetiva e solidária, que possibilita demonstrar interesse, atenção, sentimentos e possibilidades. Expressa por meio de sorrisos, conversas, brincadeiras, esclarecimentos sobre os procedimentos, orientações e estímulos para o autocuidado, que favorecem o alívio das sensações de medo, dor, preocupação, angústia e pânico. A comunicação viabiliza uma relação dialógica ao acolher a palavra do outro, oportunizando a escuta, a troca de informações e a demonstração de disponibilidade.

Outra estratégia explicitada nos estudos é a linguagem não verbal, sendo expressa com o emprego do silêncio, do toque, do afago, dentre outros atos que se complementam para que a comunicação aconteça de forma terapêutica e eficaz. Assim, a comunicação não verbal pode complementar a informação 
verbal, oferecendo indícios sobre emoções ou mesmo controlar/regular os relacionamentos ${ }^{(11)}$, como demonstram os achados a seguir:

Processo de aproximação entre pessoas que demonstram sentimentos mútuos de empatia, compreensão, cumplicidade, afeto e respeito ${ }^{(12)}$.

Pelo diálogo vivido os seres buscam compreender o dito e o não dito na inter-relação. Assim, entende-se que o dialógico no ser-com-o-outro lança um novo olhar, uma nova possibilidade de ser, saber e fazer, de uma nova percepção de encontro de cuidado em Enfermagem ${ }^{(13)}$.

Nas atitudes de interação também ocorrem ações que estimulam a aproximação do outro numa relação intersubjetiva como ao colocar-se à disposição e importar-se com cliente, valorizando seus sentimentos, sua subjetividade, sua individualidade e sua autonomia. Atitudes estas exemplificadas nos estudos selecionados em ações como chamar o indivíduo pelo nome e observar acontecimentos cotidianos que passam com o mesmo, evidenciando, desta forma que o sujeito existe como pessoa e possui identidade distinta dos demais.

A atitude de interação também pode ser expressa pela forma com que a equipe de enfermagem e interdisciplinar exerce ações sustentadas na flexibilidade, na capacidade de adequação de condutas às demandas individuais, no compromisso ético e na valorização dos espaços do sujeito no processo assistencial.

No tocante aos valores e sentimentos é vislumbrado o amor, a amizade, a afetividade, a empatia, a confiança, a credibilidade, a responsabilidade, o respeito ao outro, a privacidade e a compreensão das diferenças como ferramentas importantes no processo interativo e que favorecem o exercício da sensibilidade.

Em relação ao trabalho da Enfermagem propriamente dito, são referenciados como instrumentos de interação as atividades lúdicas, a interdisciplinaridade, o trabalho em equipe, a ação reflexiva e criativa dos profissionais, a visita de enfermagem, a habilidade de negociação, troca e reciprocidade na busca de relações éticas e interpessoais.

\section{Unidade temática 2: $\mathrm{O}$ processo interativo e suas finalidades}

As interações entre os seres são as bases para a construção do cuidado de Enfermagem, ora voltado para o indivíduo, ora para os grupos de pessoas, mas sempre concebendo "o social como uma condição humana fundamental, pois o ser humano não vive senão em relação com o outro"(10).

O processo interativo tem por finalidade favorecer o encontro entre pessoas e o estabelecimento de vinculo entre profissional, paciente e sua família cuidadora. Desta forma a interação evita o distanciamento afetivo e minimiza o isolamento dos clientes bem como o estresse emocional e o medo, ampliando o autoconhecimento, a autoaceitação e a reflexão crítica.

A interação e o diálogo permitem estabelecer e atingir objetivos em comum, que propiciam a troca de experiências e conhecimentos, momentos de reflexão, compartilhamento de ideias e decisões, culminando no enriquecimento mútuo e transformação dos envolvidos visando qualificar o atendimento. Ainda, objetiva resgatar o valor da pessoa humana, entendendo as diferenças e respeitando as peculiaridades individuais, evidenciando no movimento da interação enfermeiro-cliente uma oportunidade para a humanização do cuidado.

A interação também é vislumbrada como um processo agregador, pois viabiliza o trabalho em equipe, a inclusão da família no contexto de atenção à saúde, tanto no acesso aos serviços como na participação nos procedimentos enquanto acompanhante, como ilustram as seguintes falas:

Através do relacionamento, pode-se estabelecer vínculos que potencializem o healing, que tragam sentido para a existência, que transcendam o físico, conectando o mundo interior dos seres, numa relação transpessoal ${ }^{(14)}$

[...] a comunidade em geral é favorecida através dos conhecimentos repassados mediante atividades desenvolvidas pelo grupo ${ }^{(15)}$.

O contato interativo entre pessoas que sofrem dos mesmos problemas é uma forma de inclusão e estruturação de redes de suporte, enriquecendo o cuidado e permitindo o estabelecimento de novas formas de cuidar por meio da troca de vivências, experiências, aprendizados e sentimentos.

Desta forma, a interação no ambiente de cuidado é em síntese: um processo de inter-retro-ação contínuo entre todos os envolvidos no cuidado, tendo como objetivo mutuo a atenção às necessidades humanas em sua totalidade, sendo utilizada como ferramenta do cuidado e estabelecida pela relação horizontal e dialógica entre os seres, permeada pela prática comunicativa e relacional que culmina com o cuidado em saúde e enfermagem.

\section{Unidade temática 3: Cuidado mediado e ampliado pelo processo interativo}

O cuidado foi vislumbrado como resultado de múltiplas interações, sendo subjetivo e indo ao encontro às necessidades individuais, fato que em muitas ocasiões o torna pouco visível ou concreto, bem como tornando sua definição mais ampla e maior do que determinados conceitos, mensurações ou medidas. O cuidado está dissolvido nas ações e emoções compartilhadas e construídas com o outro em um processo interacional mutuo ${ }^{(16)}$.

Corroborando este pensamento, o cuidado de enfermagem é reconhecido como relacional, recíproco, alicerçado na ação solidária, comprometido e igualitário entre profissionais e pacientes, permitindo o entrelaçamento de atitudes e interações orientadas para a abertura de espaço em direção a dimensão objetiva e sensível do cuidado. As falas, a seguir, ressaltam o processo interacional do cuidado.

Constitui-se em um conjunto de relações entre sujeitos, em um sistema operante que, em suas relações internas com seus componentes e em suas relações com o ambiente 
externo, é capaz de se auto-organizar, de se auto determinar, pressupondo rupturas e superações ${ }^{(17)}$.

A enfermagem mantém uma contínua convivência com os clientes, de modo que isso possibilita grandes oportunidades de interação ${ }^{(18)}$.

Assim, o cuidado é ampliado pelo processo de interação, quando apresenta diálogo, troca de informações, experiências e sentimentos ${ }^{(19)}$. Apenas por meio da articulação das ações e interações entre os participantes do cuidado, é iniciado o caminhar para o trabalho que atende às necessidades multidimensionais dos indivíduos, resgatando a visão holística do ser humano em sua integralidade e totalidade, culminando num cuidado humanizado.

\section{Unidade temática 4: Interação prejudicada}

O ambiente de trabalho deveria ser um local que proporciona o desenvolvimento de relações humanas sustentáveis, favorecendo o estabelecimento de inter-relação entre atitudes e conhecimentos que proporcionam "decisões compartilhadas, aproximações não convencionais e convívios entre diferentes" ${ }^{\prime \prime 19)}$.

Porém é comum a verificação de ocorrência de situações de conflito no ambiente de cuidado, sendo que estas relações entre ordem/desordem/auto-organização ocorrem conferindo estado de equilíbrio dinâmico e tornando necessário o estabelecimento de movimentos em direção a coexistência sem a exclusão e a convivência harmoniosa em uma mesma realida$\mathrm{de}^{(1)}$, como ilustram os achados a seguir:

O que se encontrou foram os profissionais distantes da atenção direta e nas ocasiões em que ela se caracterizava era através de um modo negativo de ser/ estar com o outro $^{(20)}$.

A falta de informações e instruções adequadas e necessárias, no decorrer do trabalho de parto e do parto, é percebida pelas pacientes como descaso, provocando nelas o sentimento de indignação, pois se sentem abandonadas e desrespeitadas ${ }^{(21)}$.

Nesta perspectiva, foram evidenciados nos dados formas de interação prejudicada, como, por exemplo, o uso de poder nas relações interpessoais por parte de enfermeiros e médicos na execução de suas atividades assistenciais bem como nos relacionamentos com os demais membros da equipe, acompanhantes e clientes Foi exposto ainda que o uso da linguagem é fator de distanciamento e exclusão, quando empregada de forma codificada pelos profissionais, sendo barreira à comunicação democrática.

No entanto, há como contra ponto o acúmulo de funções para o enfermeiro, o surgimento de dificuldades pessoais e estabelecimento de momentos de ausência e fragilidades nos vínculos com a equipe, o que oportunizada situações de conflitos entre os membros da equipe de enfermagem, acompanhantes e pacientes.
No que tange às dificuldades na execução do trabalho, estão incluídas: excesso de burocracia, salário incompatível com a responsabilidade, descrição das rotinas como fator negativo devido à inflexibilidade, gasto excessivo de tempo com o gerenciamento da unidade, sentimento de angústia e estresse devido às más condições de trabalho, causadas pela falta de recursos materiais e humanos, bem como aparente descompromisso com a execução do trabalho por membros da equipe evidenciado pelo elevado absenteísmo.

No tocante às dificuldades nas interações profissional/ paciente é expresso o medo de contágio pelas doenças, o rodízio de profissionais, a confusão no reconhecimento da atuação de cada profissional, bem como, clientes e familiares insatisfeitos e desgastados com os serviços de saúde.

A condição de desordem crescente- interação prejudicada - torna possível surgir do ser uno, isolado do convívio e da interação, levando ao afastamento que culmina com a negligência, desconforto e descuidado consigo e com os demais componentes do ciclo vital. Cuidar em saúde demanda empregá-lo em adequada quantidade, não sobrepor ações mecanizadas e rotineiras às de afeto e atenção, já que, justamente, o "equilíbrio dinâmico"(2) favorece a obtenção de resultados terapêuticos satisfatórios nos mais diversos cenários em saúde.

Assim, o processo de viver e interagir deve transcender as diversas dificuldades de relacionamento, inclusive as formas de poder e de dominação, pois a teia da vida consiste em "redes dentro de redes", ou seja, não há acima ou abaixo, e sim, redes inseridas dentro de outras ${ }^{(6)}$.

\section{Unidade temática 5: Interação como instrumento de ges- tão e formação do sistema de saúde}

A Enfermagem desempenha um papel fundamental no processo assistencial e gerencial dos serviços em saúde. Além da demanda tecnológica que vem sendo incorporada ao cotidiano da profissão, há uma preocupação com os aspectos relacionados ao ambiente de trabalho. Assim, os dados revelam que o grande desafio de quem gerencia o cuidado é utilizar as relações como forma de tecnologia, visando satisfazer as necessidades dos indivíduos ao mesmo tempo em que valoriza os trabalhadores e os usuários.

Evidenciou-se que as reuniões em equipe tem sido um instrumento adequado para discutir coletivamente as questões de interesse comum, oportunizando a abertura para críticas bem como amplia o compartilhamento de poder no processo decisório. O exercício da gestão baseada em relações horizontais com os membros da equipe minimiza o autoritarismo, favorecendo liderança participativa, a experimentação da corresponsabilidade e do pró-atividade por todos, em busca da prática efetiva das ações em saúde.

O sistema de saúde é constituído por um conjunto de componentes em uma teia viva, dinâmica, repleta de particularidades e peculiaridades que o distinguem de máquinas ou de conjuntos tecnológicos. "A máquina pode ser controlada; de acordo com a compreensão sistêmica da vida, o sistema vivo só pode ser perturbado"(22), ou seja, o sistema de saúde é extremamente complexo e se "auto-eco-organiza" em um conjunto onde não há uma verdade absolutamente certa, mas 
contínuo diálogo com a incerteza ${ }^{(1)}$, como demonstram as seguintes falas:

O sistema de cuidado em saúde se configura por movimentos/ondulações de relações, interações e associações em estruturas e propriedades de processos auto-eco-organizadores de dimensões variadas de cuidado $^{(23: 469)}$.

[...] a interdisciplinaridade faz com que profissionais com objetivos comuns solidarizem-se com os outros sujeitos permitindo uma autonomia que integre os componentes da decisão, do desenvolvimento de capacidades, da criatividade, da auto determinação mas, antes de tudo, do pluralismo que marca o nosso tempo ${ }^{(24: 330)}$.

Assim, o sistema de saúde é apontado como uma organização multidimensional composta por todos os constituintes do cuidado envolvidos em um nível interacional mais amplo. Tem a perspectiva do exercício do trabalho com metas, visando a multi e interdisciplinaridade, a possibilidade de novas alianças com o paciente, a promoção de ações mais solidárias, terapêuticas e culturalmente centradas no sistema familiar de cuidados.

Ainda revelam o desejo da construção de relações mais harmônicas e humanas valorizando o sujeito trabalhador e o ser cuidado, considerando o contexto sócio-cultural do cliente e o uso da comunicação efetiva na abordagem educativa, preconizando a não realização de julgamentos nas relações de cuidado.

\section{CONCLUSÕES}

A partir dos textos publicados, produto de investigação e de reflexão, a interação é apresentada como elemento essencial do cuidado associada às características como empatia, respeito, responsabilidade, ética, compaixão, relação de ajuda, comunicação e compreensão. Os vários contextos, concepções e dimensões do processo interativo apresentados nos artigos, às vezes explícita, outras implicitamente, demonstram que os enfermeiros têm contemplado a interação como elemento essencial para o cuidado e como preocupação para a pesquisa.

Todos os textos afirmam que o cuidado existe com a interação em atitudes éticas, de respeito, de responsabilidade e de sensibilidade fundamentada na abertura ao diálogo. Além disto, também trazem o cuidado como processo interativo ou trabalho em equipe, caracterizado pelo diálogo de iguais e pela horizontalidade de saberes. A interação é ainda apresentada pela qualidade dos encontros enfermeiro-sujeito, enfermeiro-equipe e enfermeiro-instituição, fato que contribui para a satisfação do usuário e para o alcance de resultados positivos para o plano terapêutico.

Estas constatações revelam que as interações constituem o cerne do cuidado sendo objeto-produto das ações em saúde, estabelecidas por meio de formas de comunicação que possibilitam o desenvolvimento das relações e interações que culminam no agir em saúde e enfermagem.

\section{REFERÊNCIAS}

1. Morin E. A cabeça bem-feita: repensar a reforma, reformar o pensamento. 6ed. Rio de Janeiro: Bertrand; 2002.

2. Boff L. Saber cuidar: ética do humano- compaixão pela terra. 11ed. Petrópolis: Vozes; 2004.

3. Capra F. O ponto de Mutação. 25ed. São Paulo: Cultrix; 2005.

4. Prochet TC, Silva MJP. Proxêmica: as situações reconhecidas pelo idoso hospitalizado que caracterizam sua invasão do espaço pessoal e territorial. Texto \& contexto enferm 2008; 17(2):321-6.

5. Boff L. A fé na periferia do mundo. 2ed. Petrópolis: Vozes; 1979.

6. Capra F. A teia da vida. 4ed. São Paulo: Cultrix; 1999.

7. Gil AC. Métodos e Técnicas de Pesquisa Social. São Paulo: Atlas; 2006.

8. Minayo MCS. O desafio do conhecimento: pesquisa qualitativa em saúde. 9ed. São Paulo: Hucitec; 2006.

9. Morin E. Ciência com consciência. 10ed. Rio de Janeiro: Bertrand; 2007.

10. Erdmann AL, Andrade SR, Mello ALSF, Meirelles BHS. Gestão nas práticas de saúde na perspectiva do cuidado complexo. Texto \& Contexto Enferm 2006; 15(3): 483-91.

11. Santos CCV, Shiratori K. A influência da comunicação não verbal no cuidado de enfermagem. Rev Bras Enferm 2005; 58(4): 434-37.

12. Tanj S, Novakoski LER. O cuidado humanístico num contexto hospitalar. Texto \& Contexto Enferm 2000; 9(2): 800-11.

13. Paula CC, Crossetti MGO. O acontecer do cuidado de enfermagem ao ser-criança que convive com AIDS: ser; saber e fazer compartilhado. Rev Gaúcha Enferm 2005; 26(1): 102-14.

14. Vianna ACA, Crossetti MGO. O movimento entre cuidar e cuidar-se em UTI: uma análise através da Teoria do Cuidado Transpessoal de Watson. Rev Gaúcha Enferm 2004; 25(1): 56-69.

15. Almeida LHRB, Rocha FC, Nascimento FCL, Campelo LM. Ensinando e aprendendo com portadores de Esclerose Múltipla: relato de experiência. Rev Bras Enferm 2007; 60(4): 460-463.

16. Klock P, Rodrigues ACL, Backes DS, Erdmann AL. Vislumbrando as conexões intersubjetivas do cuidado de enfermagem. Av Enferm 2008; 26(1):13-21. 
17. Vaz MRC, Loureiro MM, Cabreira GO, Sena J. Trabalhador em saúde: subjetividade e auto-organização. Texto \& Contexto Enferm 2002; 11(1):50-65.

18. Squassantel ND, Alvim NAT. Relação equipe de enfermagem e acompanhantes de clientes hospitalizados: implicações para o cuidado. Rev Bras Enferm 2009; 62(1): 11-7.

19. Lima RC, Bretas JRS. A corporalidade do cliente segundo representações de estudantes de enfermagem. Rev Bras Enferm 2006; 59(6): 727-33.

20. Sousa FGM; Terra MG, Erdmann AL. Health services organization according to the intersectoral perspective: a review. Online Braz J Nurs [serial online] 2005 [cited 2008 set 2]; 4(3): [5 screens]. Available from: http://www. uff.br/objnursing/index.php/nursing/article/view/44/17.

21. Maldolosso ARM, Patrício ZM. Refletindo sobre a qualidade do cuidado de enfermagem: uma proposta assistencial transformadora. Texto \& Contexto Enferm 2000; 9(2)pt2 562-76.

22. Caron OAF, Silva IA. Parturiente e equipe obstétrica: a difícil arte da comunicação. Rev Latinoam Enferm 2002; 10(4): 485-492.

23. Capra F. As conexões ocultas: ciência para uma vida sustentável. 4a. ed. São Paulo: Cultrix; 2005.

24. Erdmann AL, Mello ALSF, Meirelles BHS, Marino SRA. As organizações de saúde na perspectiva da complexidade dos sistemas de cuidado. Rev Bras Enferm 2004; 57(4): 467-71.

25. Alves M, Ramos FRS, Penna CMM. O trabalho interdisciplinar: aproximações possíveis na visão de enfermeiras de uma unidade de emergência. Texto \& Contexto Enferm 2005; 14(3): 323-31. 